\title{
On the Role of Saffman Force in Inertial Microfluidics
}

\author{
Ali Farajpour ${ }^{1}$, Mergen H Ghayesh ${ }^{1 *}$ and Hamed Farokhi ${ }^{2}$ \\ ${ }^{1}$ School of Mechanical Engineering, University of Adelaide, Australia \\ ${ }^{2}$ Department of Mechanical and Construction Engineering, North Umbria University, UK
}

*Corresponding author: Mergen H Ghayesh, School of Mechanical Engineering, University of Adelaide, South Australia 5005, Australia.
Received Date: June 17, 2019

Published Date: June 28, 2019

\begin{abstract}
In this brief review article, the effects of Saffman force in inertial microfluidics-based systems are discussed and investigated. A short discussion regarding the applications of microfluidics, especially inertial microfluidics, is given. Then, the importance of the present investigation is illustrated. The Saffman force is mathematically formulated based on matched asymptotic expansion approach. Moreover, the physical concept of this lift force is discussed in this analysis. Finally, the influences of various physical and material parameters on the Saffman force are investigated.
\end{abstract}

Keywords: Inertial microfluidics; Ultra-small particles; Saffman force; Inertial migration

\section{Introduction}

Small-scale electromechanical devices have a great potential to revolutionize many existing fields of technologies [1]. A wide range of promising applications of these devices has recently been reported. These applications include but not limited to cell manipulation, energy harvesting, structural reinforcements, cancer diagnosis, mass sensing and drug delivery [2-5]. Smallscale electromechanical devices [6,7] are generally fabricated using microscale/nanoscale structural components involving microscale/ nanoscale beams [8-20], plates [21-28] and shells [29,30] as well as nanotubes [31-33] and fluid-conveying nanotubes [34-36]. For more information on microscale/nanoscale structural components, a reader is referred to review papers $[37,38]$. Similar to large-scale structures [39-41] in which geometric nonlinearity is likely [4248], for analyzing these components, large deformation effects are important. Last 20 years have seen a dramatic increase in the number of research studies and investigations on the mechanical and physical behavior of structural components [49-52] at smallscale levels [53,54].

One of important small-scale electromechanical devices is microfluidics, which deals with the manipulation and control of fluids and particles at microscales. This novel type of ultra small devices has extensively been used for various purposes by researchers and engineers [55,56]. For instance, in an exciting investigation by Shafiee et al. [57], using microfluidics-based technology, an acute portable biosensor was invented for detecting the human immunodeficiency virus (HIV). Furthermore, Warkiani et al. [58] fabricated a microfluidics-based device of a spiral geometry for detecting the circulating tumor cells in human blood; they showed that this technique of detection was relatively inexpensive, label-free and fast.

In addition to these fascinating applications, inertial microfluidics has lately been utilised for malaria detection [59].

Inertial microfluidics, in which the geometry and internal forces play a critical role, belongs to the passive type of microfluidics. Due to comparatively low costs, simple design and high efficiency, the popularity of inertial microfluidics among scientists and researchers has dramatically increased in recent years. In the channel of inertial microfluidics, there are a number of various internal forces such as drag, wall-induced, and Saffman. In this brief review paper, the influences of Saffman force on ultrasmall moving particles in inertial microfluidics are focused. The concept of Saffman force is firstly discussed, and then a number of mathematical relations are given to formulate this force. The effects of different parameters on the Saffman force are lastly investigated.

\section{Saffman Force}

One phenomenon, which is commonly observed in many inertial microfluidics-based systems, is inertial migration. In this 
phenomenon, particles with a random initial distribution travel laterally to an equilibrium state during their direct movement in the channel. Let us take into account a straight microtube conveying fluid with particles. The microtube radius is denoted by $\mathrm{R}$ in this study. The equilibrium state of particles in this tube is $0.6 \mathrm{R}$. This inertial migration is highly related to wall effects. Generally, the wall of the channel of an inertial microfluidics causes two main effects. The first effect is that the presence of a wall causes a fluid velocity gradient. The second effect is particle retardation, which is associated with the microfluidics wall. In this short discussion, we focus on the first wall effect only.

A microfluidics wall leads to a gradient in the fluid velocity profile (i.e. shear rate), and this consequently results in a lateral lift force on particles. This lift force is technically called "Saffman force". Figure 1 depicts a spherical ultrasmall particle in a fluid flow with a constant velocity gradient (i.e. simple shear flow). Through use of matched asymptotic expansion approach, the Saffman force (Fs) on this particle is determined as

$$
F_{s}=\frac{K}{-} d_{P} U_{r} \mu_{f} \sqrt{\frac{c}{v_{f}}}
$$

in which $d_{p}, U_{r}$ and $K$ are respectively particle diameter, relative speed and Saffman constant. $\mathrm{c}_{\mathrm{g}}, \mu_{f}$ and $v_{f}$ denotes the velocity gradient, fluid viscosity and kinetic viscosity, respectively. The Saffman constant is taken as 81.2. There are a number of assumptions and simplification for obtaining Eq. (1). For more detail on that interested readers can refer to Refs. [60] and [61]. It is worth mentioning that the kinetic viscosity is associated with fluid viscosity by $v_{f}=\mu_{f} / \rho_{f}$ where $\rho_{f}$ is fluid density. It is important to note that the magnitude of relative speed between the particle and fluid determines the force direction. As indicated in Figure 1 , the Saffman force is exerted towards the region in which there are higher relative speeds. The magnitude of the relative speed is simply obtained by the following relation

$$
U_{r}=\left|\vec{U}_{P}-\vec{U}_{f}\right|
$$

Here $\vec{U}_{P}$ and $\vec{U}_{f}$, respectively, represent particle and fluid velocities.

\section{Ultrasmall}

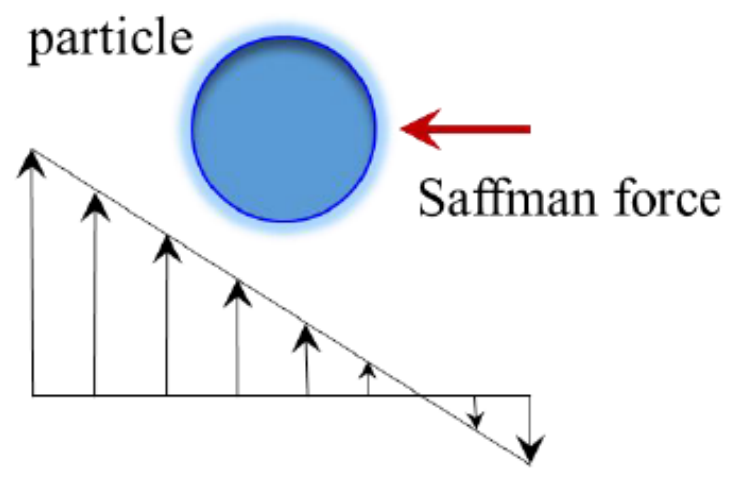

Figure 1: Saffman force acting on an ultra-small particle.
From Eq. (1), it is found that the Saffman force depends on a number of geometrical and material parameters such as fluid viscosity, particle diameter, and speed gradient. As the diameter of the ultra-small spherical particle increases, the Saffman force sees a noticeable increase in its magnitude. Furthermore, increasing the relative speed $\left(\mathrm{U}_{\mathrm{r}}\right)$ leads to a proportional increase in this force as well. However, the rate of this increase in the Saffman force is considerably less than that of particle diameter according to Eq. (1). Another important parameter for the Saffman force is velocity gradient. Higher velocity gradients result in slightly higher Saffman forces.

\section{Conclusion}

The Saffman force induced due to the speed gradient in a simple shear flow has been discussed. A mathematical framework was reviewed so as to theoretically analyses the Saffman force in inertial microfluidics-based systems. Finally, the effects of a number of physical and material parameters on this lift force were discussed based on the given mathematical relationships. It was concluded that the particle diameter has an important

increasing impact on the Saffman force. Moreover, the Saffman force proportionally increases with increasing the relative speed inside the inertial microfluidics. Furthermore, when the speed gradient increases, the Saffman force gradually becomes larger.

\section{Acknowledgement}

None.

\section{Conflict of Interest}

No conflict of interest.

\section{References}

1. Hornyak GL, Tibbals HF, Dutta J, Moore JJ (2008) Introduction to nanoscience and nanotechnology. CRC press, Florida, USA.

2. Farokhzad OC, Langer R (2009) Impact of nanotechnology on drug delivery. ACS nano 3(1): 16-20.

3. Xiong B, Ren K, Shu Y, Chen Y, Shen B, et al. (2014) Recent developments in microfluidics for cell studies. Adv Mater 26(31): 5525-5532.

4. Wang ZL, Wu W (2012) Nanotechnology-enabled energy harvesting for self-powered micro-/nanosystems. Angewandte Chemie International Edition 51(47): 11700-11721.

5. Ferrari M (2005) Cancer nanotechnology: Opportunities and challenges. Nat Rev Cancer 5(3): 161-171.

6. Ghayesh MH, Farokhi H, Alici G (2016) Size-dependent performance of micro gyroscopes. International Journal of Engineering Science 100: 99111.

7. Ghayesh MH, Farokhi H, Amabili M (2013) Nonlinear behaviour of electrically actuated mems resonators. International Journal of Engineering Science 71: 137-155.

8. Ghayesh MH, Amabili M, Farokhi H (2013) Nonlinear forced vibrations of a microbeam based on the strain gradient elasticity theory. International Journal of Engineering Science 63: 52-60.

9. Ghayesh MH (2018) Functionally graded microbeams: Simultaneous presence of imperfection and viscoelasticity. International Journal of Mechanical Sciences 140: 339-350.

10. Ghayesh MH (2018) Dynamics of functionally graded viscoelastic microbeams. International Journal of Engineering Science 124: 115-131. 
11. Ghayesh MH, Farokhi H (2015) Chaotic motion of a parametrically excited microbeam. International Journal of Engineering Science 96: 3445.

12. Ghayesh MH, Amabili M, Farokhi H (2013) Three-dimensional nonlinear size-dependent behaviour of Timoshenko microbeams. International Journal of Engineering Science 71: 1-14.

13. Ghayesh MH, Farokhi H, Amabile M (2013) Nonlinear dynamics of a microscale beam based on the modified couple stress theory. Composites Part B: Engineering 50: 318-324.

14. Ghayesh MH, Farokhi H, Amabili M (2014) In-plane and out-of-plane motion characteristics of microbeams with modal interactions. Composites Part B: Engineering 60: 423-439.

15. Farokhi H, Ghayesh MH, Amabili M (2013) Nonlinear dynamics of a geometrically imperfect microbeam based on the modified couple stress theory. International Journal of Engineering Science 68: 11-23.

16. Farokhi H, Ghayesh MH (2015) Thermo-mechanical dynamics of perfect and imperfect Timoshenko microbeams. International Journal of Engineering Science 91: 12-33.

17. Farokhi H, Ghayesh MH, Gholipour A, Hussain S (2017) Motion characteristics of bilayered extensible Timoshenko microbeams. International Journal of Engineering Science 112: 1-17.

18. Ghayesh MH, Farokhi H, Gholipour A (2017) Oscillations of functionally graded microbeams. International Journal of Engineering Science 110: 35-53.

19. Ghayesh MH, Farokhi H, Gholipour A (2017) Vibration analysis of geometrically imperfect three-layered shear-deformable microbeams. International Journal of Mechanical Sciences 122: 370-383.

20. Farajpour MR, Shahidi A, Farajpour A (2018) Resonant frequency tuning of nanobeams by piezoelectric nanowires under thermo-electromagnetic field: A theoretical study. Micro \& Nano Letters 13(11): 16271632.

21. Gholipour A, Farokhi H, Ghayesh MH (2015) In-plane and out-of-plane nonlinear size-dependent dynamics of microplates. Nonlinear Dynamics 79(3): 1771-1785.

22. Ghayesh MH, Farokhi H (2015) Nonlinear dynamics of microplates. International Journal of Engineering Science 86: 60-73.

23. Farokhi H, Ghayesh MH (2015) Nonlinear dynamical behaviour of geometrically imperfect microplates based on modified couple stress theory. International Journal of Mechanical Sciences 90: 133-144.

24. Ghayesh MH, Farokhi H, Gholipour A, Tavallaeinejad M (2018) Nonlinear oscillations of functionally graded microplates. International Journal of Engineering Science 122: 56-72.

25. Farajpour MR, Shahidi AR, Farajpour A (2018) A nonlocal continuum model for the biaxial buckling analysis of composite nanoplates with shape memory alloy nanowires. Materials Research Express 5(3): 035026.

26. Farajpour MR, Shahidi AR, Hadi A, Farajpour A (2018) Influence of initial edge displacement on the nonlinear vibration, electrical and magnetic instabilities of magneto-electro-elastic nanofilms. Mechanics of Advanced Materials and Structures.

27. Farajpour MR, Shahidi AR, Farajpour A (2019) Frequency behavior of ultrasmall sensors using vibrating sma nanowire-reinforced sheets under a non-uniform biaxial preload. Materials Research Express 6(6): 065047.

28. Farajpour MR, Rastgoo A, Farajpour A, Mohammadi M (2016) Vibration of piezoelectric nanofilm-based electromechanical sensors via higherorder non-local strain gradient theory. Micro \& Nano Letters 11: 302307.

29. Farokhi H, Ghayesh MH (2018) Nonlinear mechanical behaviour of microshells. International Journal of Engineering Science 127: 127-144.

30. Farajpour A, Rastgoo A, Farajpour M (2017) Nonlinear buckling analysis of magneto-electro-elastic cnt-mt hybrid nanoshells based on the nonlocal continuum mechanics. Composite Structures 180(15): 179191.

31. Ghayesh MH, Farajpour A (2018) Nonlinear mechanics of nanoscale tubes via nonlocal strain gradient theory. International Journal of Engineering Science 129: 84-95.

32. Farajpour A, Ghayesh MH, Farokhi H (2019) Large-amplitude coupled scale-dependent behaviour of geometrically imperfect NSGT nanotubes. International Journal of Mechanical Sciences 150: 510-525.

33. Farajpour M, Shahidi A, Tabataba'i-Nasab F, Farajpour A (2018) Vibration of initially stressed carbon nanotubes under magneto-thermal environment for nanoparticle delivery via higher-order nonlocal strain gradient theory. The European Physical Journal Plus 133: 219.

34. Farajpour A, Farokhi H, Ghayesh MH, Hussain S (2018) Nonlinear mechanics of nanotubes conveying fluid. International Journal of Engineering Science 133: 132-143.

35. Ghayesh MH, Farokhi H, Farajpour A (2019) Global dynamics of fluid conveying nanotubes. International Journal of Engineering Science 135: 37-57.

36. Farajpour A, Farokhi H, Ghayesh MH (2019) Chaotic motion analysis of fluid-conveying viscoelastic nanotubes. European Journal of Mechanics-A/Solids 74: 281-296.

37. Farajpour A, Ghayesh MH, Farokhi H (2018) A review on the mechanics of nanostructures. International Journal of Engineering Science 133: 231-263.

38. Ghayesh MH, Farajpour A (2019) A review on the mechanics of functionally graded nanoscale and microscale structures. International Journal of Engineering Science 137: 8-36.

39. Ghayesh MH (2018) Nonlinear vibration analysis of axially functionally graded shear-deformable tapered beams. Applied Mathematical Modelling 59: 583-596.

40. Gholipour A, Ghayesh MH, Zander A (2018) Nonlinear biomechanics of bifurcated atherosclerotic coronary arteries. International Journal of Engineering Science 133: 60-83.

41. Gholipour A, Ghayesh MH, Zander A, Mahajan R (2018) Threedimensional biomechanics of coronary arteries. International Journal of Engineering Science 130: 93-114.

42. Ghayesh MH, Amabili M, Farokhi H (2013) Coupled global dynamics of an axially moving viscoelastic beam. International Journal of Non-Linear Mechanics 51: 54-74

43. Ghayesh MH, Moradian N (2011) Nonlinear dynamic response of axially moving, stretched viscoelastic strings. Archive of Applied Mechanics 81(6): 781-799

44. Ghayesh MH, Yourdkhani M, Balar S, Reid T (2010) Vibrations and stability of axially traveling laminated beams. Applied Mathematics and Computation 217(2): 545-556.

45. Ghayesh MH (2012) Subharmonic dynamics of an axially accelerating beam. Archive of Applied Mechanics 82(9): 1169-1181.

46. Ghayesh MH, Kazemirad S, Darabi MA (2011) A general solution procedure for vibrations of systems with cubic nonlinearities and nonlinear/time-dependent internal boundary conditions. Journal of Sound and Vibration 330(22): 5382-5400.

47. Ghayesh MH, Kazemirad S, Reid T (2012) Nonlinear vibrations and stability of parametrically exited systems with cubic nonlinearities and internal boundary conditions: A general solution procedure. Applied Mathematical Modelling 36(7): 3299-3311.

48. Kazemirad S, Ghayesh MH, Amabili M (2013) Thermo-mechanical nonlinear dynamics of a buckled axially moving beam. Archive of Applied Mechanics 83(1): 25-42.

49. Farokhi H, Ghayesh MH, Amabili M (2013) Nonlinear resonant behavior of microbeams over the buckled state. Applied Physics A 113(2): 297307. 
50. Farokhi H, Ghayesh MH, Hussain S (2016) Large-amplitude dynamical behaviour of microcantilevers. International Journal of Engineering Science 106: 29-41.

51. Farokhi H, Ghayesh MH (2018) Supercritical nonlinear parametric dynamics of Timoshenko microbeams. Communications in Nonlinear Science and Numerical Simulation 59: 592-605.

52. Farokhi H, Ghayesh MH (2017) Nonlinear resonant response of imperfect extensible Timoshenko microbeams. International Journal of Mechanics and Materials in Design 13(1): 43-55.

53. Farokhi H, Ghayesh MH (2018) On the dynamics of imperfect shear deformable microplates. International Journal of Engineering Science 133: 264-283.

54. Farokhi H, Ghayesh MH (2018) Nonlinear mechanics of electrically actuated microplates. International Journal of Engineering Science 123: 197-213.

55. Whitesides GM (2006) The origins and the future of microfluidics. Nature 442(7101): 368-373.
56. Pandey CM, Augustine S, Kumar S, Kumar S, Nara S, et al. (2018) Microfluidics based point-of-care diagnostics. Biotechnol J 13(1): 201700047.

57. Shafiee H, Jahangir M, Inci F, Wang S, Willenbrecht RB, et al. (2013) Acute on-chip HIV detection through label-free electrical sensing of viral nanolysate. Small 9(15): 2553-2563.

58. Warkiani ME, Khoo BL, Wu L, Tay AKP, Bhagat AAS, et al. (2016) Ultrafast, label-free isolation of circulating tumor cells from blood using spiral microfluidics. Nature protocols 11(1): 134-148.

59. Warkiani ME, Tay AKP, Khoo BL, Xiaofeng X, Han J, et al. (2015) Malaria detection using inertial microfluidics. Lab on a Chip 15(4): 1101-1109.

60. Zhang J, Yan S, Yuan D, Alici G, Nguyen NT, et al. (2016) Fundamentals and applications of inertial microfluidics: A review. Lab on a Chip 16(1): 10-34.

61. Saffman PG (1965) The lift on a small sphere in a slow shear flow. Journal of fluid mechanics 22(2): 385-400. 